into a teschenite by the incoming of purple titanaugite and basic soda-lime felspars, but the latter rock is penetrated by irregular veins of the analcite-syenite.

This occurrence is interesting, inasmuch as there is only one other occurrence of alkali-syenites in the British area, namely, the borolanite and associated syenites of Sutherlandshire. These, however, are probably of Cambrian age. The Ayrshire occurrences are being investigated by the writer with the aid of a Royal Society grant, and it is hoped that an account of these alkalic rocks will be published in a short time.

University of Glasgow, December 9.

\section{Collected Works of Sir William Herschel.}

I BEG to direct attention to a pressing need, namely, the publication of the collected works of Sir William Herschel. The investigations of this great man are practically inaccessible to the vast majority of modern astronomers, and the result is that few have any acquaintance with his writings, or know them only second-hand. In my relations with American astronomers I have met no one who has made a close study of Herschel's papers, and in going over them myself have been obliged to obtain them from distant libraries and abstract the contents by laborious processes. I have been equally impressed with the deep insight into the laws of nature which Herschel shows, and the slight extent to which his conclusions and methods are known to modern workers. Surely you will be willing to lend your voice to the praiseworthy task of awakening the British public to a national duty. When writing the life of Herschel for the "Encyclopædia Britannica" thirty years ago, the late Prof. Pritchard directed attention to the necessity of the publication of Herschel's collected works; but meanwhile nothing has been done. Italy has published the collected works of Galileo, Holland the collected works of Huyghens, while France has published the collected works of several of her great mathematicians and astronomers, \&c., as those of Lagrange, Laplace, Fourier, Fermat, \&c., and now the Swiss, with commendable effort, are trying to publish the vast collected works of Euler.

Herschel's writings are not very voluminous, and probably could be comprised in one large or two moderate sized volumes; and it seems certain that a thousand copies of them could be sold within reasonable time, so that a good publishing house might safely undertake the risk; but in order to give the work a national stamp it would need supervision by an official committee of the Royal Society, or the Royal Astronomical Society, of which Herschel was the first president.

U.S. Naval Observatory, Mare Island, California,

November 20

\section{An International Map of the World.}

I HAVE read with much interest, in NATURE of December 2, the communication by Sir Duncan Johnston. I must, however, confess that two of his propositions tend to damage the very principle of uniformity aimed at by the original idea.

For if, in the preparation of the map of closely populated districts, another scale (in the details) is to be adopted, the general idea conveyed by the map will be misleading.

The same is the case with altitudes. It is necessary to take into consideration the fact that, in all probability, the metre-unit will be adopted throughout the world in the time necessary for the preparation and issuing of the proposed maps. In the meantime, it should be noted on the sheets for foot-countries: $\mathrm{Im} .=3$ feet.

\section{Nagybecskerek, Hungary, December 6.}

\section{E. BÁTHORI.}

Witu reference to Dr. Bathori's letter on the article which appeared in NATURE of December 2, on the $\mathrm{I} / \mathrm{I}, 000,000$ scale international map, I agree with him to the extent that I am fully impressed with the importance of uniformity so far as it can be attained without detriment to the value of the map, but I consider that in some cases uniformity can only be obtained at too great a price.

Dr. Bathori demurs to my suggestion that the detail NO. 2094, VOL. 82$]$ shown should not be absolutely uniform throughout the world. I can best illustrate my view that too hard and fast a uniformity should not be insisted on by stating a concrete case. The committee proposes, and I think rightly, to show on the map lines of telegraph and post offices. In sparsely settled countries, for example Rhodesia, such information would be useful, and could easily be shown on the map. In the populous London district such information would be of no value, even if it could be shown, and I think that the practical utility of the map would be increased in this case by some departure from strict uniformity. Other similar cases might be given.

With regard to the other point mentioned by Dr. Bathori I am afraid I cannot agree with him that the metre will be adopted throughout the worid, and I certainly hope that the completion of the international map will not be postponed until the metre is generally used. In the past and the present the foot has been and is used as the unit of measurement in the United States of America, in Great Britain and Ireland and its colonies and dependencies; practically all records are in terms of that unit, and it must be many years before this unit can be changed, if it ever is. If the countries named do not exceed in area and population those which have adopted metrical measurements, they are, at any rate, large enough to merit consideration. I see no reason why the altitudes in this very large and populous area should be shown on the map in terms of a unit not generally used by their people, nor, on the other hand, do I see any cause why the large and populous countries which have adopted the metrical system should have their altitudes expressed in feet.

It seems to me that, provided the unit adopted is legibly marked on the map and subject to some give and take where the two systems meet, countries using the foot should have their altitudes expressed in feet, and those using the metre in metres. I do not think this would cause material difinculty. The practical advantages of this course seem to me to justify some departure from rigid uniformity.

Eastbourne, December io.

Duncan A. Johnston.

\section{Positions of Birds' Nests in Hedges.}

DURING the autumn and winter of the past three years I have been observing the distribution of birds' nests as regards position in the hedges. In the fields around this village the following facts are noticed. In hedges running north and south (facing east and west), by far the greater number of nests are found to the east of a line through the length of the hedge. In hedges running east and west (facing north and south), very few are on the north side, some in the centre, but most to the south of the line through the length of the hedge. There seems to be a very good reason why this should be the case, but it would not do to state reasons without more evidence. I have not seen this matter noticed in any book or "paper," and it would be interesting to know how the majority of the nests in other parts of the country are placed. The present is a good time for such observations.

St. Faith's, Norfolk, December 2.

\section{J. H. Tull Walsh.}

\section{Uranium Ore as a Remedy.}

WITH reference to Mr. H. Warth's letter in NAtURE of November II (p. 38), it may be of interest to record a fact which has come under my notice while engaged in the development of a uranious mine in Turkestan. The ore is oxidised and calcareous, and contains uranium, vanadium, and copper, radium being present in accordance with Prof. Rutherford's formula, which gives the quantity of it in relation to the uranium. The uranium is on the average 3.8 per cent., but in some places reaches the ratio of 30 per cent. and more. Until now the work in the mine has proceeded only in the summer time, and in the winter season the workmen have migrated to the neighbouring coal and copper mines. As I know from the literature of the subject that vanadium and uranium are toxic substances, I instruct the workmen to wash their hands well before going to their dinner and after their work. "We 